\title{
Domestic Solar - Aero - Hydro Power Generation System
}

\author{
Deepak Sekar ${ }^{1}$, Niranjana Venkatesh ${ }^{1}$ \\ 1. Department of Electrical and Electronics Engineering, Adhiparasakthi Engineering College, \\ Melmaruvathur, India
}

\begin{abstract}
In the past few years there is a global transformation on technology and researches which aims to energy savings through the usage of renewable sources in many applications. With the need for usage of renewable energy increasing day by day, more efficient and innovative systems are to be created. The system created has to be a combination of the non-conventional resources, as implementing only one may not suffice the energy requirement. It has to be understood that every bit helps in saving energy, and so, domestic needs being the largest can be supplemented by smaller individual units of renewable sources. This has to be highly efficient and requiring less maintenance. A thought given to the above requirements of the new age has brought a new perspective to energy saving. The result has been created by combining a solar-aero-hydro system which is designed for efficient domestic usage.
\end{abstract}

Keywords: domestic, renewable energy, water tank, wind power

\section{Introduction}

The technology behind the generation of power requires but a turning force. With this sole thought, a turbine is made to move with the help of two forces alternatively acting on it. Abundant wind energy acts upon the turbine to generate power. This can be advocated by the potential of hydro power. Whenever the water tank needs to be filled, the water falling into the tank is first forced onto the turbine. Thus there is wise use of the force of the falling water.

Thus if the filling up of water is scheduled to such a time when the wind sources are low, it would be more efficient. The system has been designed carefully to respond to both the water and wind forces. This case study develops a method to serve domestic power supply by using a system which combines energy production from a single turbine operating both on wind and water forces. The system has been designed carefully to respond to both the water and wind forces. The system ensures that there is no wastage of water by splashing. Hence this forms a hybrid system consisting of solar - aero and hydro generation system. The other important devices of the system are the generator, battery, control unit, inverter.

\section{Renewable Energy - Statistics}

At the end of $2010^{[1]}$ Energy production was $430 \mathrm{TWh}$, which is about $2.5 \%$ of worldwide electricity usage; and has doubled in the past three years.

Several countries have achieved relatively high levels of wind power penetration, such as $21 \%$ of stationary electricity production in Denmark, $18 \%$ in Portugal $16 \%$ in Spain, $14 \%$ in Ireland and $9 \%$ in Germany in $2010^{[3]}$.

As of May 2009, 80 countries around the world are using wind power on a commercial basis ${ }^{[2]}$.

From the pie chart ${ }^{[1]}$ shown in Fig. 1, we deduce the following comparative study.

- The generation of power using solar source is approximately 0.5 to $1 \%$ of the total renewable generation.

- The generation of power using hydro resources is approximately $60 \%$ of the total renewable energy generation.

- The generation of power using wind resources is approximately $10 \%$ of the total renewable energy generation.

- The ratio of renewable energy to the non-renewable energy power generation is 1:7.

- Concentrating on power generation using hydro and wind resources, this ratio can be improved.

- The exhaustion of resources such as coal and oil can be delayed by wise implementation of renewable sources such as wind and hydro which is abundantly available for domestic usage. 

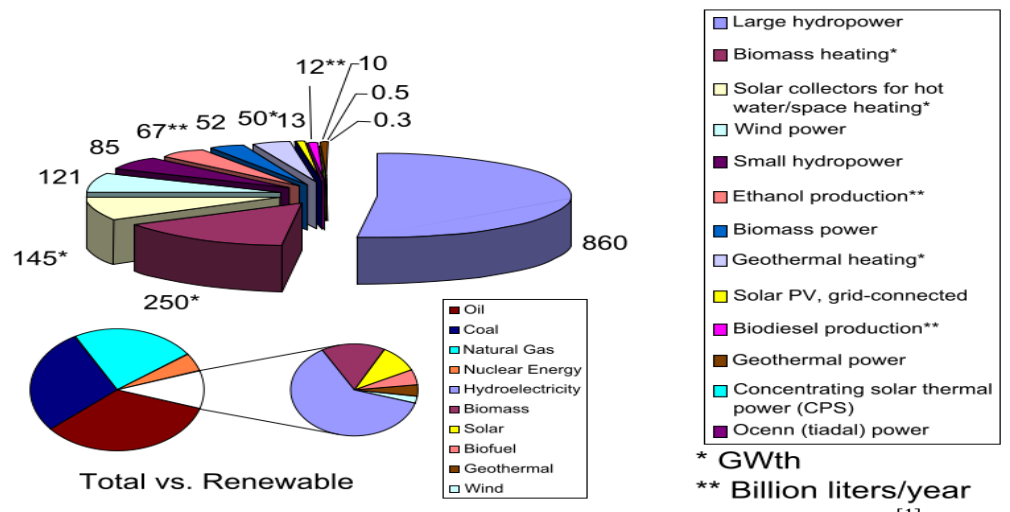

Figure 1. Renewable Energy statistics at the end of $2012^{[1]}$

Table 1. Top 10 wind power producing countries (February 2011)

\begin{tabular}{|l|l|}
\hline \multicolumn{1}{|c|}{ Country } & $\begin{array}{c}\text { Wind power } \\
\text { capacity (MW) }\end{array}$ \\
\hline China & 44,733 \\
\hline United States & 40,180 \\
\hline Germany & 27,215 \\
\hline Spain & 20,676 \\
\hline India & 13,066 \\
\hline Italy & 5,797 \\
\hline France & 5,660 \\
\hline United Kingdom & 5,204 \\
\hline Canada & 4,008 \\
\hline Denmark & 3,734 \\
\hline
\end{tabular}

The graph shown in Fig. 2 depicts the annual distribution of solar energy measured on horizontal surface. All the measurements of solar energy were recorded in a point inside the urban area.

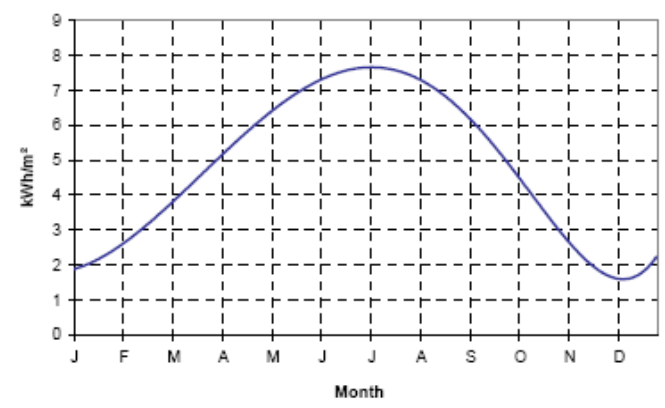

Figure 2. Annual distribution of solar radiation in urban area (horizontal surface) ${ }^{[6]}$

\section{Model Description}

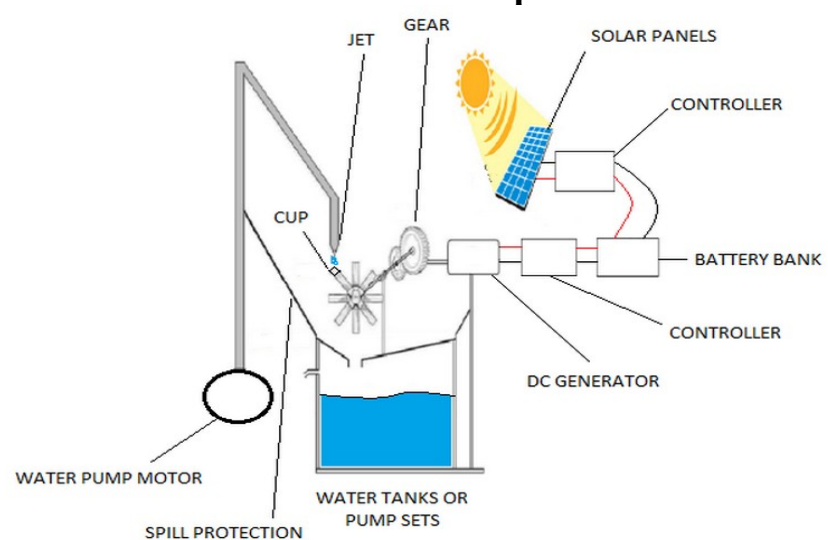

Figure 3. Model of the Proposed System 


\subsection{Working- The Water Cycle}

- The motor pumps the water into the tank through a pipe.

- The height of the pipe is increased for creating a head and the water is made incident on the cups at the edge of the turbine blades.

- Potential energy of water $\square$ Kinetic Energy $\square$ Mechanical Energy $\square$ Electrical Energy.

\subsection{Working-The Aero Cycle}

- The water source cannot be used when the water tank is full.

- Yet, the turbine can be put to use.

- By making the wind incident on the blades it works as a wind turbine.

- Hence a single turbine works as a water and wind turbine, depending upon the source.

\subsection{Working- The Solar Cycle}

- The solar panels are integrated to this system which is of the same voltage level of the generator.

- This will generate enough amount of solar power which is stored in the batteries.

\subsection{Spill Protection}

When water is made incident on the turbine, it may spill out. To avoid this, a spill protection is placed at both ends. Therefore, water and material are saved.

The main perspectives of this system are

\section{The Technology}

1. Operation at low wind velocity and low water pressure.

2. Low resistance to operation.

3. Low product cost.

4. Less space requirements.

\subsection{Dual Purpose Turbine}

\section{Design Specifications}

The material used for the design of the dual turbine is fibre glass or epoxy resin. Experimental values of turbine diameter to jet diameter are given below which indicates that as the wheel diameter to jet diameter ratio increases along with turbine rpm the efficiency of the turbine also increases.

Table 2. Turbine specifications

\begin{tabular}{|l|l|l|l|l|}
\hline D wheel / D jet (m) & 6.5 & 7.5 & 10 & 20 \\
\hline Ns (rpm) & 70 & 76 & 85 & 90 \\
\hline n turbine & 0.82 & 0.86 & 0.89 & 0.90 \\
\hline
\end{tabular}

\subsection{Zones of Cup Inclination}

The cups in the turbine runners and the jet should be positioned such that the specified inclinations for above specified different processes are always maintained.

- Initial feeding process: $\left(\theta \mathrm{j}=0 \circ \ldots 10^{\circ}\right)$

- Last stage of inflow: $\left(\theta j=0 \circ \ldots-10^{\circ}\right)$

- Last stage of outflow: $\left(\theta j=-10^{\circ} \ldots-50^{\circ}\right)$

- Series of droplets: $\left(\theta \mathrm{j}=-50^{\circ} \ldots \infty\right)$

\subsection{Generator}

This generator is a variable-speed wind generator system with a boost converter and pitch angle control system. The generator system has two speed control modes for the wind velocity.

1. The control mode of low wind velocity regulates the armature current of the generator with the boost converter according to the windmill speed. Therefore the output voltage is greater than the input voltage.

2. The control mode of high wind velocity (i.e.) when the turbine exceeds the rated speed regulates the pitch angle of the wind turbine with the pitch angle control system to control the windmill speed.

The proposed system simplifies the maintenance, improves the reliability, reduces the cost in compare with variable- speed wind generation system using PWM converter. 


\subsection{Power available from solar resource}

\section{Calculations}

The annual distribution of solar energy varies according to seasons and the graph below depicts the solar radiation level in $\mathrm{kWh} / \mathrm{m}^{2}$ on earth surface in urban area.

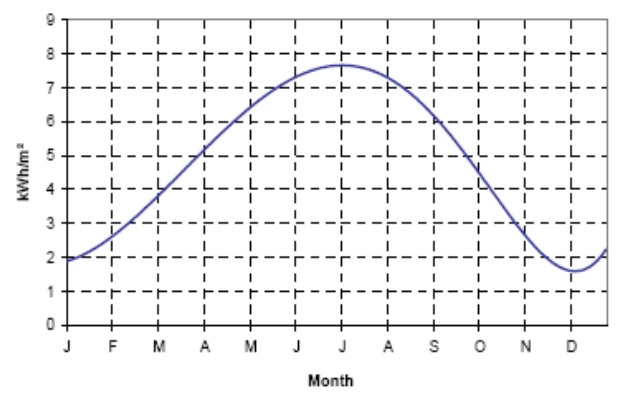

Figure 4. Annual distribution of solar radiation in urban area on earth's surface(horizontal surface ${ }^{[6]}$

The average available power from solar radiation per year is approximately equal to $55 \mathbf{k W h} / \mathbf{m}^{2}$ on the earth's horizontal surface.

\subsection{Power available from water and wind resources}

A turbine can draw power from the flow of a body of water and wind without necessarily changing its height. In this case, the available power ${ }^{[4]}$ is:

$$
\mathrm{P}=1 / 2 \rho \Phi \mathrm{v}^{2}
$$

Where $v$ is the speed of the water, $\varphi$ is the rate of fluid flow.

But, the rate of fluid flow is given by:

$$
\Phi=\mathrm{Av}
$$

Where $A$ is the area through which the water passes for water resource and $\mathrm{A}$ is the area of the blades for wind resource, hence, the Power available is given by:

$$
\mathrm{P}=1 / 2 \rho \mathrm{Av}^{3}
$$

An example calculation for water resource:

We are given the following data:

- $\quad$ Diameter of pipe, $\mathrm{d}=0.15 \mathrm{~m}$

- Water speed, $\mathrm{v}=5 \mathrm{~m} / \mathrm{sec}$

- Water density, $\rho=1000 \mathrm{~kg} / \mathrm{m} 3$

Inserting the value radius of the pipe as radius of the swept area we have:

$\mathrm{d} / 2=\mathrm{r}=0.075 \mathrm{~m}$

$\mathrm{A}=\pi \mathrm{r}^{2}$

$=\pi \times 0.075^{2}$

$\mathrm{A}=0.0176625 \mathrm{~m}^{2}$

We can then calculate the power converted from the wind into rotational energy in the turbine using equation:

$\mathrm{P}($ avail $)=(1 / 2) \rho \mathrm{Av}^{3}$

$P($ avail $)=1.103 \mathrm{~kW}$

$$
=0.5 \times 1000 \times 0.0176625 \times 5^{3}
$$

An example calculation for wind resource:

Note: The power coefficient value should be multiplied with the result. The theoretical maximum power efficiency of any design of wind turbine is 0.59 (i.e. no more than $59 \%$ of the energy carried by the wind can be extracted by a wind turbine). This is called the "power coefficient $C p$ " ${ }^{[5]}$

We are given the following data:

- Blade length, $\mathrm{l}=1 \mathrm{~m}$

- Wind speed, $\mathrm{v}=12 \mathrm{~m} / \mathrm{sec}$

- Air density, $\rho=1.23 \mathrm{~kg} / \mathrm{m} 3$

- Power Coefficient, $\mathrm{Cp}=0.4$

Inserting the value for blade length as the radius of the swept area we have:

$1=\mathrm{r}=1 \mathrm{~m}$

$\mathrm{A}=\pi \mathrm{r}^{2}$ 


$$
=\pi \times 1^{2}
$$

$\mathrm{A}=3.14 \mathrm{~m}^{2}$

We can then calculate the power converted from the wind into rotational energy in the turbine using equation:

$$
\begin{aligned}
\mathrm{P}(\text { avail }) & =(1 / 2) \rho \mathrm{Av}^{3} \mathrm{Cp} \\
& =0.5 \times 1.23 \times 3.14 \times 12^{3} \times 0.4 \\
\mathbf{P}(\text { avail }) & =\mathbf{1 . 3 3} \mathbf{~ k W}
\end{aligned}
$$

\section{Possible Innovation In Future}

- The system may be implemented in all pump sets in farm lands, where there is usage of abundant water resource every day.

- Commercial buildings, industries and all educational institutions may implement this technology to reduce their dependence on conventional energy.

- This system when installed in all residences will make green powered houses.

\section{Advantages}

- A combination of renewable energy resources are put to efficient usage.

- Pollution-less system is developed.

- Low maintenance is required.

- Only one-time investment is required.

- The cost of power generation is less.

- Dependency on conventional resources is reduced.

- Renewable energy is used to the maximum efficiency.

- Operation at low wind velocity and low water pressure.

- Low resistance to operation.

- Low product cost.

- Less space requirements.

- Provides entrepreneurship and employment opportunities.

\section{Conclusion}

Renewable energy resources are abundant in nature. They have to be wisely used for effective energy generation. A sustainable future requires this. The theoretical calculation of power available proves that if hybrid technologies are made available at low cost, power can be generated even in residences. Conventional resources are on the verge of exhaustion. It is in the hour of need that we devise new ideas for saving them. The wise implementation of the ideas in already existing systems, for example, the water tank chosen here, will prove to be a boon to mankind. The main objective of this system is the small scale energy production. If the proposed method is widely implemented, the savings are considerable. Solar, Wind and Hydro energy, a "fascinating view of future" will definitely fulfill our energy needs.

\section{Acknowledgements}

We express our heartfelt gratitude to the Innovation and Entrepreneurship Development Centre, New Delhi and the Department of Electrical and Electronics Engineering, Adhiparasakthi Engineering College, Melmaruvathur, Tamil Nadu for having funded our project.

[1] "Renewables Global Status Report 2009 Update” (PDF).

[2] "Wind Power Increase in 2008 Exceeds 10-year Average Growth Rate". Worldwatch.org. Retrieved 2010-08-29.

[3] "World Wind Energy Report 2010" (PDF).Report. World Wind Energy Association. February 2011. Retrieved 30-April-2011.

[4] Donald G. Fink and H. Wayne Beaty, "Standard Handbook for Electrical Engineers, Eleventh Edition", McGraw-Hill, New York, 1978 .

[5] Gijs A.M. van Kuik, “The Lanchester-Betz-Joukowsky Limit “, Wind Energy. 2007; 10:289-291.

[6] Constantinos A.Bouroussis“"Outdoor lighting using renewable energy sources," National Technical University of Athens School of Electrical and Computer Engineering, Photometry Laboratory 